results achieved, of the possibility of again extending arable agriculture over some or all of the remainder of the cleared land. It is not expected that more than 45,000 out of the 65,000 acres cleared at Urambo will be available for agriculture for the harvest of 1951 ; but 60,000 acres will be ready later. Of the 20,000 acres felled in the Southern Province, 7,000 acres will be available for agriculture for the 1951 harvest, and during the current wet season a further 40,000 acres are being felled with the two landclearing teams built up for that purpose. Thereafter, the Corporation proposes drastically to reduce the tractor force to the minimum required to complete the remaining operations on this 40,000 acres and to adopt a slower and cheaper method of land clearing involving the substitution of hand labour for part of the work at present done by machines. Under this scheme the same tractor force might be expected to fell an additional 15,000 acres of land per year, and the Corporation contemplates that the same acreage would be brought into cultivation each year, giving by 1957 a total of 105,000 acres fully cleared for agriculture and a further $35,000-45,000$ acres in various stages of preparation. In this revised scheme all three areas, with one exception at Kongwa, will be farmed in units of 1,500-6,000 acres, under intensive supervision by men who can gain an intimate knowledge of the land which they farm, instead of the 30,000-acre units originally proposed. The Corporation stresses the need for continuity of agricultural operations over a period of at least seven years in the interests both of efficiency and of the morale of the staff which, it is now admitted, has suffered from past uncertainties and changes of plan.

The Government is satisfied that some assurance of continuity is reasonable and indicates its firm intention, provided the costs do not greatly exceed the estimates, that funds should be provided to enable farming operations to continue for seven years. It approves the proposal for a review in 1954 before deciding on what scale further felling and clearing should be undertaken. It is estimated that over this seven-year period a further $\mathfrak{£} 6$ million will be required, without allowing for any contingencies or for any bush clearing after 1954. While the Corporation does not consider that on the basis of the new plan its needs alone would justify the com. pletion of the new part of Mtwara, in the light of decisions by the Tanganyika Government and the East African Railways and Harbours Administration to construct and improve feeder roads and to extend the railway sixty miles westward from the groundnut area, the Corporation has agreed, with the concurrence of the Government, to complete the port and the railway connecting it with the existing line.

The conclusions on which this revised plan is based are clearly stated in the appendix. First, the attempt to produce crops economically on land which has been cleared for agriculture at a great cost in money and human effort must be sustained for a sufficiently long period-put at a minimum of seven years-to show conclusive results. Second, the areas selected for development are capable of giving good yields of groundnuts and have done so on the small experimental farms. The problem yet to be solved is that of reproducing something approaching these results on a large scale. It is now concluded that the groundnut is not a plant which lends itself readily to mass methods over vast aereages, and that the attainment of economic yields demands intensive farming.
Third, the elearing of ferest and bush by wholly mechanical means from land of the type occupied by the Corporation has proved impracticable within either the time or the cost envisaged in earlier plans ; it cannot be done at an economic cost in relation to the value of the arable land created. Fourth, the Corporation considers that it would be wasteful not to utilize, at least for a maximum tree-felling effort (the most efficient and economical of the mechanized operations) during the coming wet season, the accumulated resources in communications, installations, machines and man-power which have been built up over the past three years. Finally, provision must also be made from the capital remaining at the disposal of the Corporation to cover commitments, mainly worthless, from the past and for some reserve against unforeseen contingencies in the execution of any revised plan.

The plan formulated is accordingly designed to establish, by agricultural practices and scientific experiments, a pattern of agriculture which will utilize economically all the cleared land available and which, if successful, will point the way to future development; to equip all the cleared land with permanent installations and adequate machinery and implements, without which the capital expenditure on land clearing will be wasted; and to establish that sense of permanence and stability without which no constructive objective can be achieved efficiently. The plan should also execute in the Southern Province the first stage, extending to 1957, of what may become, as a result of a later review of the economic prospects, a scheme to develop the total area capable of being serviced from Nachingwea, utilizing the installations, machinery and man-power already accumulated.

The revised plan thus appears to offer reasonable prospects of turning to the best account the resources already engaged and the experience gained. The technical and research aspect may possibly be overstressed, for the proposals scarcely bring out the importance of one lesson taught by the failure of the larger scheme, namely, the necessity of training the indigenous people in modern agricultural methods if balanced progress in development is to be achieved. Stress is rightly laid on the importance of morale and the necessity for reasonable compensation for the thousand or so European staff who will become redundant during the next three years; but something could well have been said of the part that Africans are to play in the scheme, for its ultimate success must also depend on the transformation of inexperienced Africans into successful farmers able and willing to reclaim and maintain their own land.

\section{CENTRAL DRUG RESEARCH INSTITUTE, INDIA}

$\mathrm{T}$ HE Council of Scientific and Industrial Research, India, launched six of its national laboratories during 1950. It has planned eleven such institutions so far, and the rernaining five its energetic director, Sir Shanti Swarup Bhatnagar, expects to launch in the course of 1951. The seventh of the series, dedicated to research on drugs, was the occasion of an impressive inaugural ceremony in a very picturesque setting in a Lucknow palace on the bank of the Gomati on February 17. 
The imperative need for a Central Drug Research Institute was stressed in 1947 by the Pharmaceutical and Drugs Committee of the Couneil, and an outline scheme for such a body was drawn up by Dr. B. Mukerji. A planning committee came into being early in the following year, and a few months later the assistant director (planning) was appointed. After examining various suggested locations, the Committee decided on Lucknow, as it is a university town with a medical college and a first-rate teaching hospital ; the Government of the State offered the historic Chattar Manzil Palace as a free gift to the Council to house the proposed Drug Research Institute.

Lucknow is proud of its many eighteenth- and nineteenth-century buildings, and of having evolved an architectural style of its own, ornate and tortuous, and often seeking to combine Mughal and Western elements. Chattar Manzil ranks high in Lucknow architecture. An army engineer, Claude Martin, built part of the Manzil; but it was later acquired and extended by successive Nawabs of Oudh. The British converted the Nawabs' harem into a club, and now renascent India is transforming it into a modern research centre. The architect and engineers of the U.P. Government and the assistant director (planning) have had a difficult task in effecting this metamorphosis. For the present, only a portion of the four-storied palace has been converted; but this covers quite 25,000 sq. ft. Certain other portions cannot be adapted without considerable expense. The alterations, including gas and water installation and fresh electric wiring, have cost about Rs. 7 lakhs. A new building would no doubt have cost about seven times this amount. When extensions become necessary, these will be planned in architectural harmony with the Lucknow-style palace. For the present, the only altogether new additions to the buildings are the gas house and the animal house. The animal house when completed and equipped will have cost about Rs. $2 \frac{1}{2}$ lakhs. Four of its rooms will be air-conditioned-showing, Sir Shanti humorously remarked, tender consideration for animals, for in the main laboratory only the director's room is being air-conditioned. A nucleus for a workshop has already been set up in one of the outhouses; but in the near future a more suitable workshop will have to be built.

The Institute will promote drug research, test and standardize drugs discovered by the Institute, provide expert advice for their further development and production, offer research facilities and advice to scientific workers, universities and industry, organize controlled clinical trials of drugs in clinics, and dis. seminate scientific knowledge relating to drugs.

To begin with, the Institute has five divisions (1) chemistry, (2) biochemistry, (3) pharmacology, (4) microbiology and parasitology, and (5) clinical science. A sixth division (botany, including pharmacognosy) is proposed for the near future. In addition to these scientific divisions, the Institute has an animal house, an intelligence and statistical section including a central library, a museum, the necessary administrative sections and a cafeteria. A first-rate herbarium would be necessary for the pharmacognosy division.

The inauguration ceremony, presided over by the Governor of the United Provinces, Sir H. P. Mody, opened with a speech by the Hon. Mr. Sri Prakasa, Minister for Natural Resources and Scientific Research, who referred to India's creditable con- tribution to ancient medicine, narrating the mythological origin of the science with the birth of Dhanvantri, physician of the gods, who brought with him the 'Three Bitters' and 'Three Astringents' - the simples out of which a pharmacopoia grew. The Premier and the Health Minister of the Uniter Provinces (the latter is also chairman of the local committee for the Institute) referred to the import ance of the drug industry in India's national economy and to the plentiful sources of drugs in India and more particularly in the United Provinces. The Hon. Rajkumari Amrit Kaur, Minister for Publie Health, also stressed the importance of the drug industry and India's contribution to early medicine, Sir Shanti Bhatnagar said that the Institute would have to be a blending place of old and new knowledge : "It will be one of the essential functions of this Institute to subject remedies used by vaids and hakims to trial and if investigations prove them to be really effective to propagate their use to save the world from misery and disease".

Pandit Nehru, in declaring the Institute open, said that he attaches great importance to research on drugs; but he has no sympathy with the "valetudinarian outlook on life", and he ridiculed the polite conversation which suggests that being healthy and robust is vulgar; he remarked that in his youth he had been fascinated by Samuel Butler's satire and the wholesome Erewhonian practice of sending criminals to hospital for treatment while awarding a term in prison to invalids. Pandit Nehru paid a tribute to the devotion and industry of those entrusted with the hard work of the initial stages of the Institute, and said that it had been lucky in having had the benefit of Sir Edward Mellanby's guidance, even though he had only been available as director for about three months. He announced that Sir Edward would be succeeded by Dr. B. Mukerjee, director of the Drug Institute in Calcutta.

The Institute has had the advantage of guidance from Colonel R. N. Chopra, to whose pioneer work on drug research tributes were paid by Sir Shanti Bhatnagar as well as by Sir Edward Mellanby. Colonel Chopra was present at the inauguration and said : "This is a great day for drug research in India". $\mathrm{He}$ complained that the cost of essential drugs has recently been mounting higher and higher, whereas the masses in India are "too poor to obtain treatment for minor ailments, to say nothing of specific remedies required to fight disease. The majority of these are of foreign origin and their cost is prohibitive because commercial firms abroad have spent enormous sums of money on their development." Drug research in India hitherto has been sporadic, unorganized and haphazard; the Institute would put it on a sound, systematic and permanent basis. Thanks to its varied climatic, meteorological and topographical features, India, Colonel Chopra pointed out, has one of the richest floras in the world. "Plants containing medicinal principles grow abundantly and about 2,000 of 11,000 species found in India are enumerated in the indigenous medicine." Even work on plant chemistry has largely confined itself to alkaloids, glucosidns and essential oils. An enormous field, yet unerplored, is open to investigators if plant research receives a new orientation in the new Institute and plant antibiotics are also studied. Recent work in India has shown the presence of substances of antibiotic nature, active against pathogenic bacteria, in common Indian plants. Collaboration between chemists, pharmacologists. botanists and micro- 
biologists in the new Institute is full of possibilities not only of scientific and academic interest but also of great practical economic importance to India.

Sir Edward Mellanby emphasized that, for a nation's health, drugs can at best form the second line of defence; the first line must always be the public health services. He referred to ancient India's contribution to the foundation of medicine, especially in the treatment of disease by plant products. It is a paradox, he said, that "whereas a large part of the plants, from which official drugs in the pharmacopoia are made, are already grown in this country, yet many of these drugs are imported in large quantities".

\section{METHODS OF LABOUR STATISTICS USED BY LONDON TRANSPORT}

IN a paper submitted to the Institute of Actuaries and entitled "Personnel Statistics and Sickness Absence Statistics", Messrs. F. H. Spratling and F. J. Lloyd, of the London Transport Executive, discuss the importance of a systematic collection of data on numbers of staff, wastage and sickness absence in a large organization. Simple enumerations of the numbers employed as well as turnover and sickness absence rates, they argue, do not form a sufficient basis for the development of a successful staff policy. Poliey should be based on a study of the age and length-of-service distribution of the population, which makes it possible to estimate the numbers of skilled and experienced staff that will be required and to calculate the financial cost of pensions and sick pay.

To meet the requirements of administrative, financial and medical planning, London Transport, which employs a hundred thousand people, has developed specialized methods of collecting and analysing personnel statistics. The information, obtained from the employees' personal record files at the various employing departments, is collected and recorded in a Central Record of Staff Statistics which consists of three files of punched cards. The Main File gives up-to-date details for each member of the active staff. A duplicate copy, made on December 31 of each year, is used to work out the age and lengthof-service distribution of the population, and appears to be a useful device for adoption in personnel departments. The Wastage File consists of cards providing information for all leavers. The Sickness Absence File consists of cards for each spell of sickness absence; this differs from systems employed elsewhere, which collect on to one card all the absences of an individual employee.

Wastage is usually measured by the labour turnover rate, which expresses the annual number of leavers as a percentage of the average number employed during the year. This rate shows similar shortcomings to the crude death-rate, which ignores demographic factors such as the age-distribution of the population, and is not suitable for comparing experiences of different populations. In vital statistics it is therefore customary to calculate age-specific mortality rates. Similar techniques can be applied to turnover statistics, and the authors describe in detail a method of calculating specific rates which refer the number of leavers in a special age and length-of-service category to the number employed in that category.
A method for making adjustments for irregular rates of recruitment is also discussed. The problem of calculating specific rates for very short periods is complex, and an alternative approach is the statistical analysis of the behaviour of new entrants in a given period of time.

Just as age-specific mortality rates are used for the construction of life-tables, so specific wastage rates can be used for constructing service-tables, and for estimating the trend of the working population. This represents an advance over the ordinary turnover rates which cannot be used for making accurate forecasts of staff changes. It is hoped that the specific wastage rates will prove a more reliable guide for estimating future employment requirements.

In the section on sickness absence, Mr. Spratling and Mr. Lloyd discuss the difficulties of collecting comparable sickness absence statistics. Absence rates are known to vary with the period for which sick employees are kept on the books. The authors advocate six months as a reasonable period. Other research workers consider a period of one month more suitable, and suggest that prolonged absentees should be kept on a special register, and excluded from the ordinary sickness returns. The authors recommend that separate records should be kept of short absences lasting less than four calendar days, and of long absences lasting four or more calendar days. This does not follow the line adopted by other organizations, which divide sickness into certified and uncertified sickness, where certified sickness may be less than four days, and the statistics are based on working days lost, not calendar days.

Mr. Spratling and Mr. Lloyd distinguish three absence-rate functions : the attack rate, which shows the average annual number of absences per worker ; the average length of sickness absence during the year; and the sickness absence rate, which is the product of the other two functions. The punchedcard system makes it possible to analyse the records by age, length of service, duration of absence and type of disease. For the latter purpose, London Transport uses the three-figure International Statist. ical Classification of Diseases and Injuries adopted in 1948 by the United Nations World Health Organization, and a discussion of suitable groupings of various diseases is included in the paper.

A number of appendixes discuss the recording and classifying of sickness absences, ways of dealing with absences occurring in separate calendar years, and methods of calculating specific absence rates. The latter refer the number of days lost by special groups of staff to the numbers employed in those particular groups. It should be pointed out that the absence rates used by London Transport are not the usual percentage absence rates used in factories, but are a measure of the number of days lost per working year, which may be 250-300 per worker, while the percentage rates refer to 100 working days.

The specific sickness absence rates, like the specific wastage rates, have the advantage that they can be used for making reasonable forecasts of the expected sickness absence of a population (given normal climatic conditions and the absence of epidemics) if particulars with regard to age, sex and length of service of the numbers exposed to risk are known. A knowledge of the likely future loss of time might prove very useful for the production, personnel and planning departments of industrial organizations. 